\title{
Influência do vanádio nas propriedades morfológicas estruturais e fotoluminescentes do titanato de zinco $\left(\mathrm{Zn}_{2} \mathrm{TiO}_{4}\right)$
}

\section{(Influence of vanadium on the morphological, structural and photoluminescent properties of zinc titanate - $\mathrm{Zn}_{2} \mathrm{TiO}_{4}$ )}

\author{
A. C. Chaves ${ }^{1}$, M. S. C. Câmara', L. L. M. Sales ${ }^{1}$, A. G. Araújo' ${ }^{2}$ I. M. G. Santos ${ }^{2}$ D. M. A. Melo' E. Longo $^{3}$ \\ ${ }^{1}$ Laboratório de Análise Térmica e Materiais, Universidade Federal do Rio Grande do Norte \\ C.P. 1662, Natal, RN 59078-970 \\ ${ }^{2}$ UFPB - CCEN - DQ - LTM, Cidade Universitária JP, PB 58059-900 \\ ${ }^{3}$ CMDMC - LIEC, Departamento de Química, UFSCar \\ suely@materiais.ufrn.br
}

\begin{abstract}
Resumo
Neste trabalho o método do precursor polimérico foi usado para obter a fase $\mathrm{Zn}_{2} \mathrm{TiO}_{4}$ dopada com $\mathrm{V}^{5+}$. As fases foram obtidas depois que o pó precursor foi submetido a diferentes temperaturas; a caracterização do composto foi feita por meio de difração de raios $X$, análise térmica e fotoluminescência. A difícil entrada do vanádio na rede polimérica conduziu à segregação na resina e também no óxido final. Depois da dopagem a temperatura de decomposição térmica foi diminuída de $438{ }^{\circ} \mathrm{C}$ a $420^{\circ} \mathrm{C}$. Os pós calcinados a $400{ }^{\circ} \mathrm{C}$ e $500{ }^{\circ} \mathrm{C}$ apresentaram uma solução sólida substitucional entre os íons metálicos $\mathrm{Ti}^{4+}$ e $V^{5+}$, além de formação de fase secundária. Uma diminuição do volume da cela unitária depois da adição de vanádio foi observada. A cristalinidade relativa e o tamanho de cristalito apresentaram uma variação de tamanho devido a difícil substituição do vanádio pelo titânio. Foram obtidos os melhores resultados de propriedade fotoluminescente para a amostra com 0,2 mol\% de vanádio.
\end{abstract}

Palavras-chave: $\mathrm{Zn}_{2} \mathrm{TiO}_{4}$, Photoluminescência, espinélio, vanádio, método Pechini.

\begin{abstract}
In this work the polymeric precursor method was used to obtain the $\mathrm{Zn}_{2} \mathrm{TiO}_{4}$ doped with $\mathrm{V}^{5+}$. The phases were obtained after calcination of the respective precursor powders at different temperatures, and their characterization was accomplished by $X$ ray diffraction, thermal analysis and photoluminescence. It was difficult for vanadium to get into the polymeric net, leading to segregation in the resin and also in the final material. After doping, the thermal decomposition temperature decreased from $438{ }^{\circ} \mathrm{C}$ to $420{ }^{\circ} \mathrm{C}$. The powders calcined at $400{ }^{\circ} \mathrm{C}$ and $500{ }^{\circ} \mathrm{C}$ presented a substitutional solid solution between $T i^{4+}$ and $V^{5+}$ metallic ions, besides secondary phase formation. A decrease of the volume unit cell after vanadium addition was observed. Relative crystallinity and crystallite size presented a random variation due to the difficulty for vanadium substituting titanium. The best results of photoluminescent properties were obtained for the sample with 0.2 mol\% of vanadium.
\end{abstract}

Keywords: $\mathrm{Zn}_{2} \mathrm{TiO}_{4}$, photoluminescence, spinel, vanadium, Pechini method.

\section{INTRODUÇÃO}

Materiais luminescentes são bastante conhecidos há um certo tempo, e eles foram estudados bastante, não só do ponto de vista científico, como também para seu potencial de aplicação tecnológica, como, abajures fluorescentes, imagens médicas de raios $\mathrm{X}$, tomógrafo computadorizado, entre outras aplicações. Durante décadas passadas, a luminescência dos materiais cerâmicos era extensivamente estudada em materiais cristalinos, em baixas temperaturas [1].

O desenvolvimento de materiais semicondutores, com propriedades ópticas ativas como fotoluminescência (FL), eletroluminescência, ou propriedades ópticas não lineares pode conduzir a novos dispositivos com desempenho superior ou a diferentes modos de atuação [2, 3]. Neste sentido, tem havido atualmente um interesse muito grande, no estudo da FL, em materiais amorfos ou materiais não estruturados. Isso é confirmado pelo intenso esforço de pesquisa, que vem sendo feito no estudo de vários tipos de FL visível, em temperatura ambiente, como por exemplo, o silício poroso [4]. Recentemente, foi desenvolvido o estudo de materiais desordenados, apresentando intensa fotoluminescência de emissão na região do visível à temperatura ambiente. Foi estudada [5] a fotoluminescência em sistemas amorfos de $\mathrm{TiO}_{2}-\mathrm{PbO}$, e verificaram que pela adição de $\mathrm{Pb}$ na estrutura amorfa, acontece um aumento no grau de desordem, e isso 
é fundamental para a obtenção do fenômeno da fotoluminescência.

$\mathrm{O}$ titanato de zinco $\left(\mathrm{Zn}_{2} \mathrm{TiO}_{4}\right)$, também representado como $\mathrm{Zn}[\mathrm{ZnTi}] \mathrm{O}_{4}$, tem estrutura espinélio inversa, do tipo $\mathrm{A}[\mathrm{AB}] \mathrm{O}_{4}$, em que os átomos ' $\mathrm{A}$ ' se encontram em sítios tetraédricos e os átomos representados entre colchetes são octaédricos. Na maior parte dos espinélios inversos, os cátions 'A' e 'B' são dispostos randomicamente nos sítios octaédricos. Todavia, em alguns casos, esses átomos se organizam formando uma estrutura menos ordenada que os espinélios normais, porém mais ordenada que nos outros espinélios inversos [6]. Hoje, o espinélio é conhecido pela sua funcionalidade, apresentando uma lista de compostos reconhecidos por possuírem uma estrutura semelhante ao mineral natural $\mathrm{MgAl}_{2} \mathrm{O}_{4}$, tais como, $\mathrm{Fe}_{1-\mathrm{x}} \mathrm{Cu}_{\mathrm{x}} \mathrm{Cr}_{2} \mathrm{O}_{4}$, que possui propriedades magnetoresistivas colossais, $\mathrm{NiFe}_{2} \mathrm{O}_{4}$, semicondutor ferrimagnético, $\mathrm{ZnAl}_{2} \mathrm{O}_{4}$, espinélio diamagnético transparente, entre outros.

$\mathrm{O}$ espinélio $\mathrm{Zn}_{2} \mathrm{TiO}_{4}$ é conhecido na literatura como material dielétrico sendo usado como componente de soluções sólidas, em composições dielétricas. O uso desse sistema é pouco conhecido, e poucos trabalhos avaliando esse material foram publicados a respeito de suas propriedades ópticas. O vanádio tem sido utilizado tanto como formador de rede, como dopante em sistemas cerâmicos no qual tem apresentado propriedades ópticas e magnéticas, contribuindo dessa forma em aplicações tecnológicas importantes [7, 8]. Dentro deste contexto, o objetivo deste trabalho foi sintetizar o pó cerâmico com estrutura espinélio $\left(\mathrm{Zn}_{2} \mathrm{TiO}_{4}\right)$ amorfo e cristalino, pelo método Pechini, fazendo a substituição do cátion $\mathrm{Ti}^{4+}$ por, $\mathrm{V}^{5+}$ em proporções de $0,1,0,2,0,4$ e 1,0\%, com o intuito de estudar a formação do composto e a obtenção da propriedade fotoluminescente.

\section{EXPERIMENTAL}

O método Pechini, também conhecido como método dos complexos poliméricos, é utilizado na obtenção de pós cerâmicos por síntese química. O processo foi originalmente desenvolvido por Pechini, com o intuito de desenvolver pós de óxidos multicomponentes, materiais dielétricos com estequiometria controlada, o que, através do método convencional, é bastante difícil. A idéia fundamental do método Pechini é obter uma distribuição randômica dos cátions, em escala atômica, em uma resina sólida e reduzir a individualidade dos diferentes íons metálicos [9, 10]. A imobilização de complexos metálicos em uma rede polimérica orgânica rígida pode reduzir a segregação dos metais garantindo, deste modo, a homogeneidade química. Os reagentes utilizados foram Ti[OCH $\left.\left(\mathrm{CH}_{3}\right)_{2}\right]_{4}$ (Aldrich), $\left(\mathrm{HOCH}_{2} \mathrm{CH}_{2} \mathrm{OH}\right.$, Merck), ácido cítrico (Vetec) e óxido de vanádio (Aldrich). O método de síntese é representado na Fig. 1.

Após todos os reagentes terem sido adicionados a solução, a mesma foi aquecida em uma temperatura de aproximadamente $90{ }^{\circ} \mathrm{C}$, o que conduziu a uma formação de um

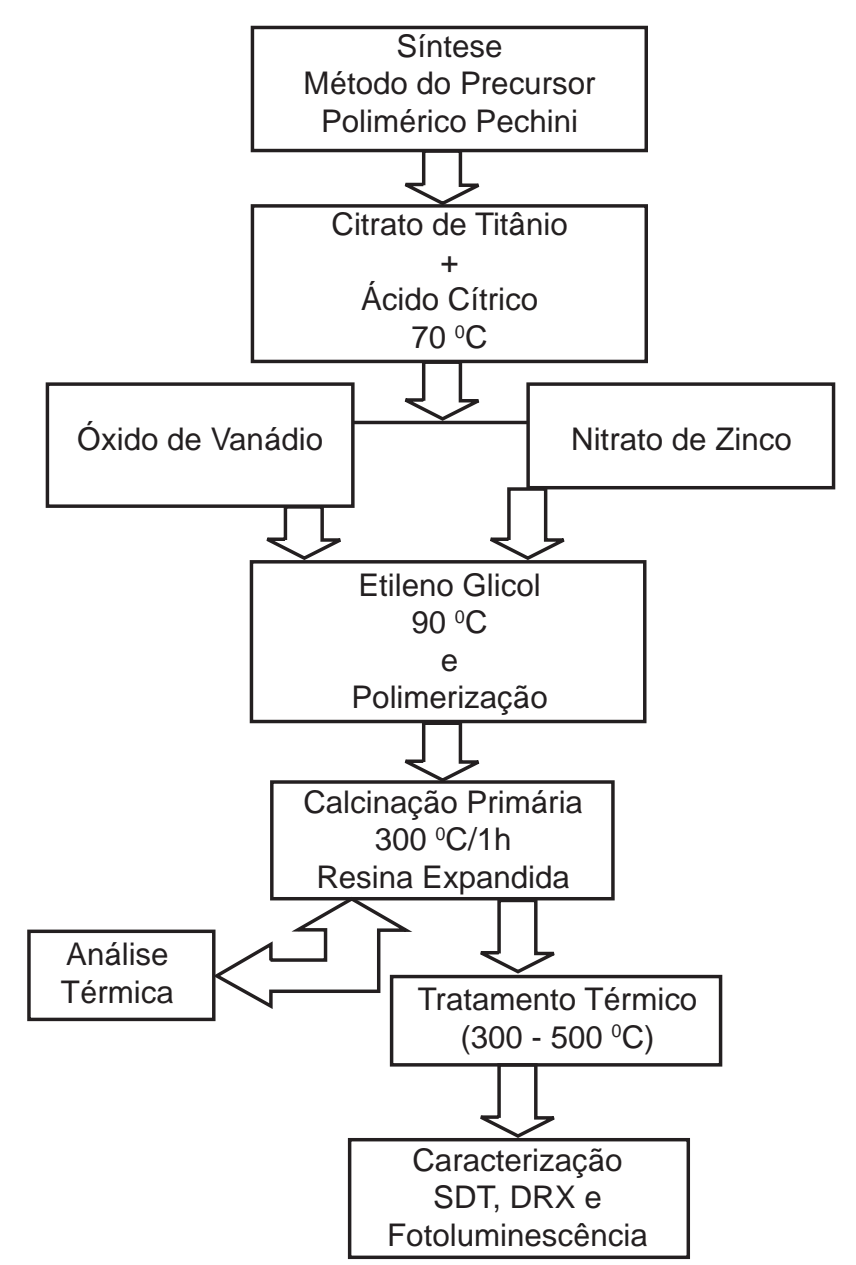

Figura 1: Fluxograma para a preparação do espinélio $\mathrm{Zn}_{2} \mathrm{Ti}_{1-\mathrm{x}} \mathrm{O}_{4}$ (x=\%.).

[Figure 1: Flow chart for the preparation of the $\mathrm{Zn}_{2} \mathrm{Ti}_{1-x} \mathrm{O}_{4}(x=\% \mathrm{~V})$ spinel.]

gel polimérico. O gel foi calcinado por $1 \mathrm{~h}$ a $300{ }^{\circ} \mathrm{C}$ que conduziu à formação de uma resina expandida, a qual foi retirada e desintegrada, e passada através de uma peneira de 100 mesh. O pó resultante foi chamado carvão. Este carvão foi moído em um moinho planetário por 60 min em uma velocidade de 150 RPM. O carvão foi calcinado a $300{ }^{\circ} \mathrm{C}$ por $32 \mathrm{~h}$ em atmosfera de oxigênio, e a 400 e $500{ }^{\circ} \mathrm{C}$ por $2 \mathrm{~h}$ em um forno tipo mufla.

Para caracterização e estudo por análise térmica, utilizouse equipamento da TA Instruments modelo SDT-2960 DSCTGA. Os ensaios foram realizados usando aproximadamente $20 \mathrm{mg}$ dos pós resultantes da pirólise a $300^{\circ} \mathrm{C}$, usando uma taxa de aquecimento de $10^{\circ} \mathrm{C} / \mathrm{min}$, numa faixa de $27-700{ }^{\circ} \mathrm{C}$, em atmosfera de ar sintético. $\mathrm{O}$ aparelho utilizado nas realizações das análises de raios $\mathrm{X}$ foi um Difratômetro Siemens D-5000, com os parâmetros de passo ajustado em 0,03 e tempo de $1 \mathrm{~s}$. As medidas de fotoluminescência foram realizadas em um equipamento U100 Jobin-Yvon, com duplo monocromador, acoplado a uma fotomultiplicadora de GaAs resfriada, juntamente com um sistema convencional de fotocontagem. A 
linha de comprimento de onda foi de $488 \mathrm{~nm}$, de um laser de íons de Argônio empregado na excitação.

\section{RESULTADOS E DISCUSSÃO}

As Figs. 2 e 3 referem-se ao comportamento térmico, onde se pode observar que independente da adição do dopante ao sistema os pós apresentaram duas etapas de termodecomposição. Onde podemos associar a primeira etapa como a eliminação de água e a segunda etapa com eliminação do $\mathrm{CO}_{2}$ do sal e cadeia orgânica. Verificou-se que ocorreu uma redução da perda de massa do cátion em relação ao carvão puro (Tabela I). Uma observação importante está relacionada ao rendimento do carvão, pois se torna difícil avaliar o rendimento da resina polimérica, devido à vasta possibilidade de concentrações das soluções de citratos metálicos, que podem ser utilizados no processo de obtenção da

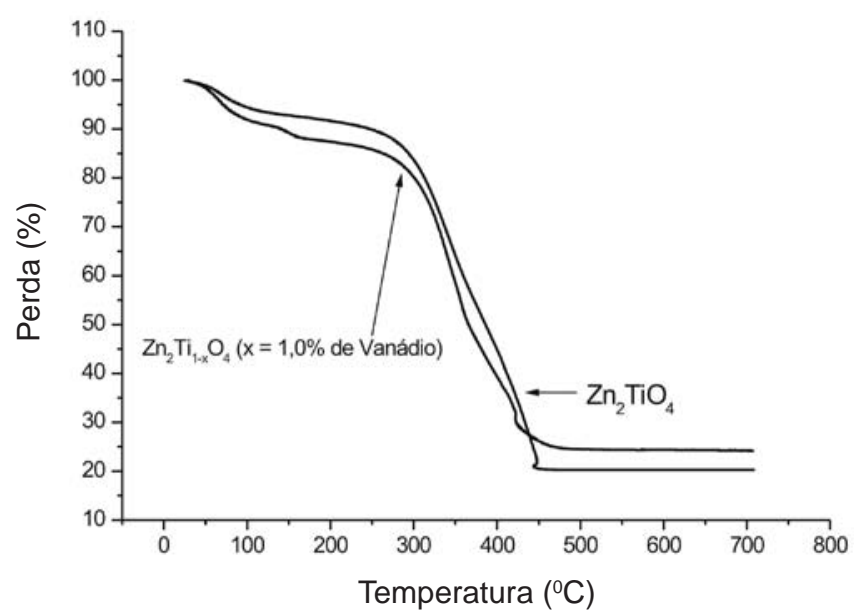

Figura 2: Curva da TG para $\mathrm{Zn}_{2} \mathrm{TiO}_{4}$ com vanádio 1,0\%.

[Figure 2: TG curve for $\mathrm{Zn}_{2} \mathrm{TiO}_{4}$ containing 1.0\% Vanadium.]

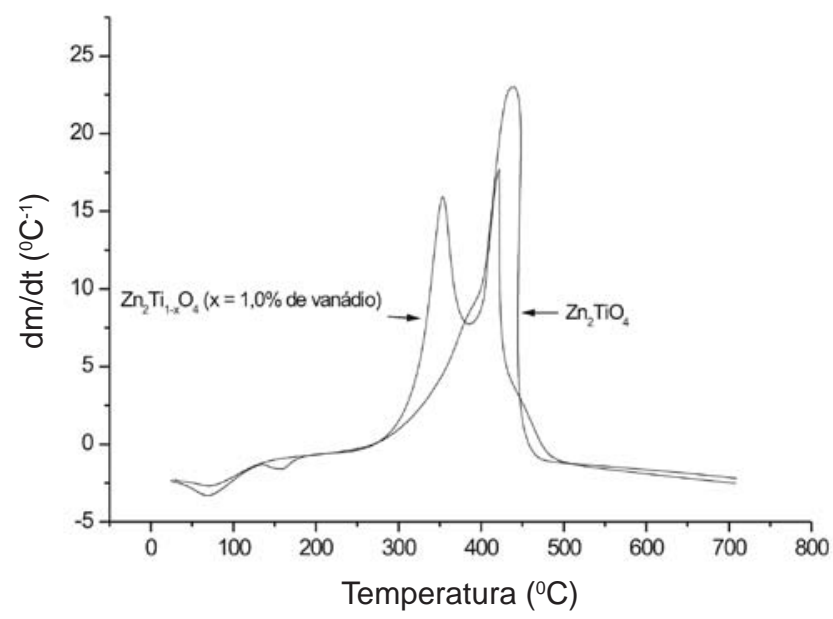

Figura 3: Curva de DTA para $\mathrm{Zn}_{2} \mathrm{TiO}_{4}$ com vanádio1,0\%. [Figure 3: DTA curve for $\mathrm{Zn}_{2} \mathrm{TiO}_{4}$ containing 1.0\% Vanadium.] síntese do $\mathrm{Zn}_{2} \mathrm{TiO}_{4}$.

A curva de Análise Térmica Diferencial, Fig. 3, realizada para a amostra de carvão pura apresentou apenas uma transição exotérmica, o que não aconteceu com a amostra do precursor dopado com vanádio, que se refletiu em dois picos exotérmicos. Um fato que podem justificar isto está relacionado ao vanádio (+5), na presença de zinco, formar grupos $\mathrm{VO}^{2+}$, que dificilmente forma compostos com ligações $\sigma \mathrm{M}-\mathrm{C}$ [11]. Isto pode levar a uma maior dificuldade de o vanádio entrar na rede polimérica, levando a uma segregação, que se reflete na presença de dois picos na curva DTA.

Com o objetivo de verificar a formação das fases do titanato de zinco, juntamente com seu cátion substitucional, os pós foram calcinados numa faixa de temperatura de 400 a $500{ }^{\circ} \mathrm{C}$ por 2 h, Figs. 4 e 5 . A $400{ }^{\circ} \mathrm{C}$, os difratogramas mostram uma grande quantidade de fase amorfa, ou seja, os picos bastante largos e pouco intensos indicam que a cristalização do material ainda está se processando. Já a $500{ }^{\circ} \mathrm{C}$, observa-se o surgimento da fase espinélio para os pós calcinados puro e dopados. Quando da introdução do cátion $\mathrm{V}^{5+}$, fases secundárias foram evidenciadas, o que está de acordo com os resultados da TG/DTA. Como o vanádio (+5) tem dificuldade de entrar na rede, em função da sua coordenação, ocorre segregação, na resina, o que leva à presença de fases secundárias no óxido final.

Com os dados obtidos a partir do programa rede 93, para cálculo de parâmetros de rede, Fig. 6, foi possível fazer o gráfico do volume da célula unitária em função da concentração do íon dopante. Segundo dados das fichas JCPDS, o volume teórico da célula unitária para a fase $\mathrm{Zn}_{2} \mathrm{TiO}_{4}$ é $605,54 \mathrm{~A}^{3}$, enquanto que o experimental foi calculado em $601,19 \mathrm{~A}^{3}$. Com a adição do vanádio ao sistema, verificouse um decréscimo desse valor, visto que o vanádio apresenta um raio iônico menor do que o titânio $\left(\mathrm{r}_{\mathrm{V}}=0,068 \mathrm{~nm}\right)$, com

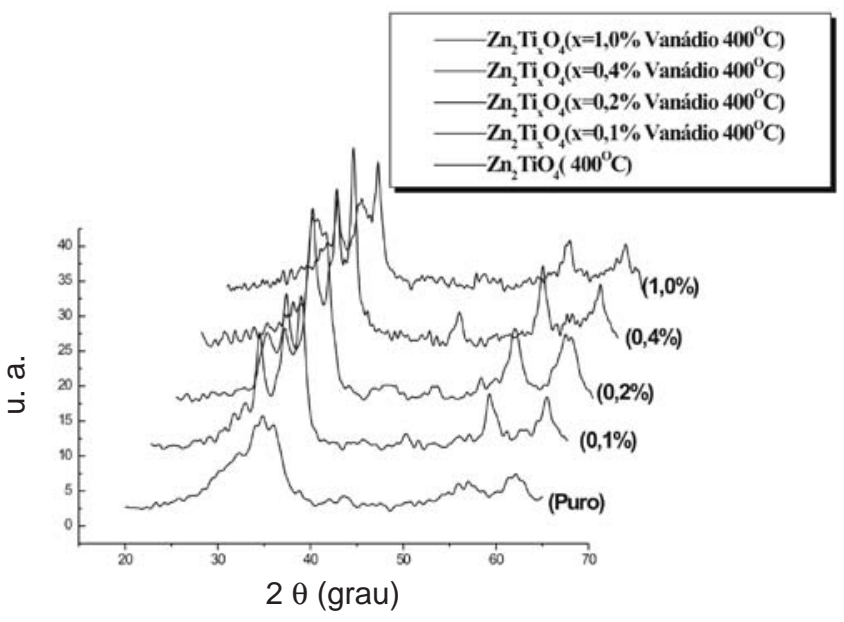

Figura 4: Difratograma de raios $\mathrm{X}$ de $\mathrm{Zn}_{2} \mathrm{TiO}_{4} \operatorname{com} 0,1,0,2$, 0,4 e $1,0 \%$ de vanádio calcinado $400{ }^{\circ} \mathrm{C}$.

[Figure 4: X-Ray diffraction pattern of $\mathrm{Zn}_{2} \mathrm{TiO}_{4}$ containing 0.1, 0.2, 0.4 and $1.0 \%$ Vanadium calcined at $400{ }^{\circ} \mathrm{C}$.] 


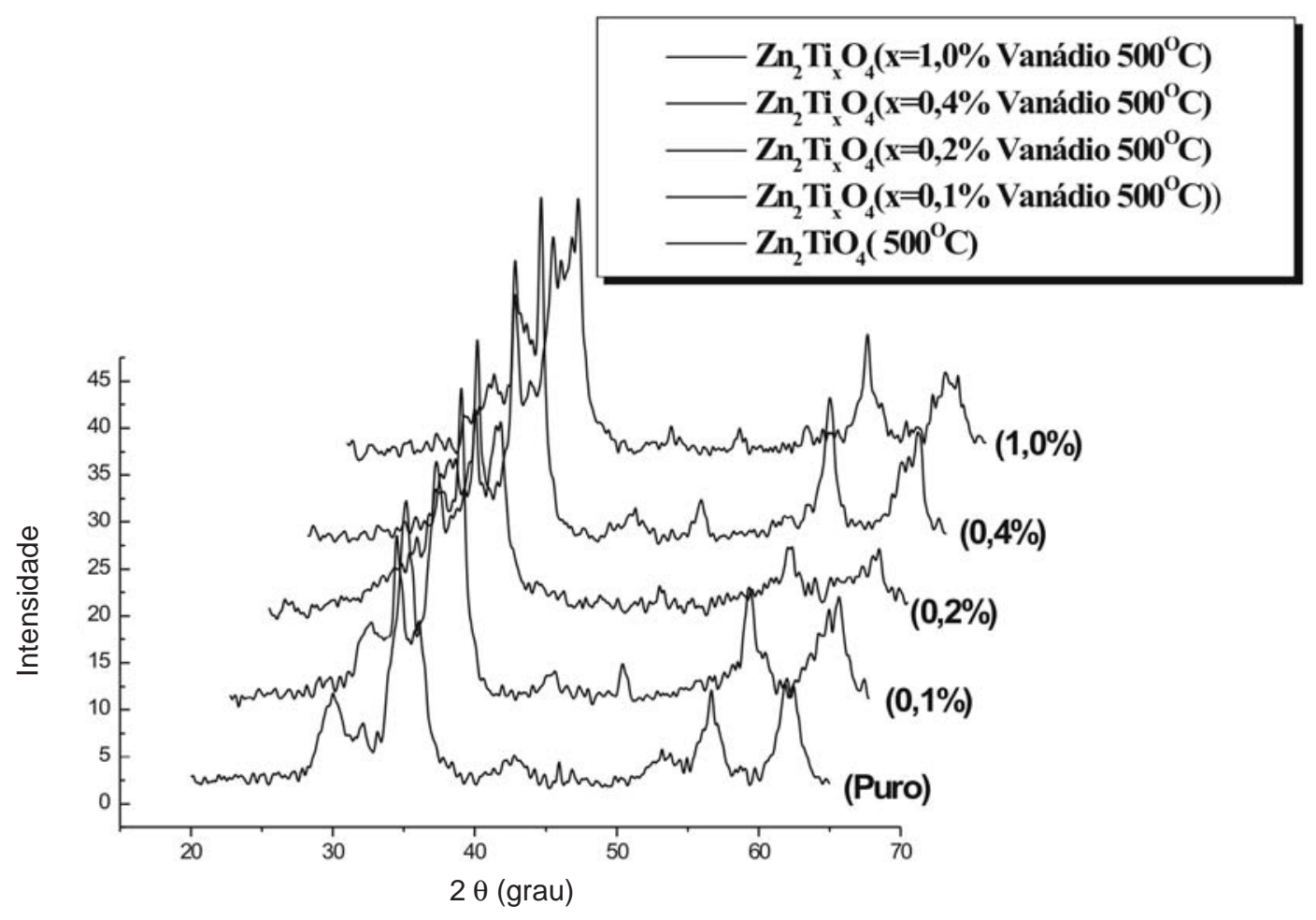

Figura 5: Difratograma de raios $\mathrm{X}$ de $\mathrm{Zn}_{2} \mathrm{TiO}_{4}$ com 0,1, 0,2, 0,4 e 1,0 \% de vanádio, calcinado a $500{ }^{\circ} \mathrm{C}$.

[Figure 5: X-Ray diffraction pattern of $\mathrm{Zn}_{2} \mathrm{TiO}_{4}$ containing 0.1, 0.2, 0.4 and $1.0 \%$ Vanadium calcined at $500{ }^{\circ} \mathrm{C}$.]

uma diferença percentual em torno de 8,7\% [12].

Realizou-se um estudo qualitativo da cristalinidade em função da quantidade de íons dopantes adicionados na estrutura, Fig. 7. Em relação ao íon vanádio, o gráfico mostra que os pontos estão dispersos e este comportamento pode ser atribuído à dificuldade do íon vanádio substituir o titânio na estrutura, sendo

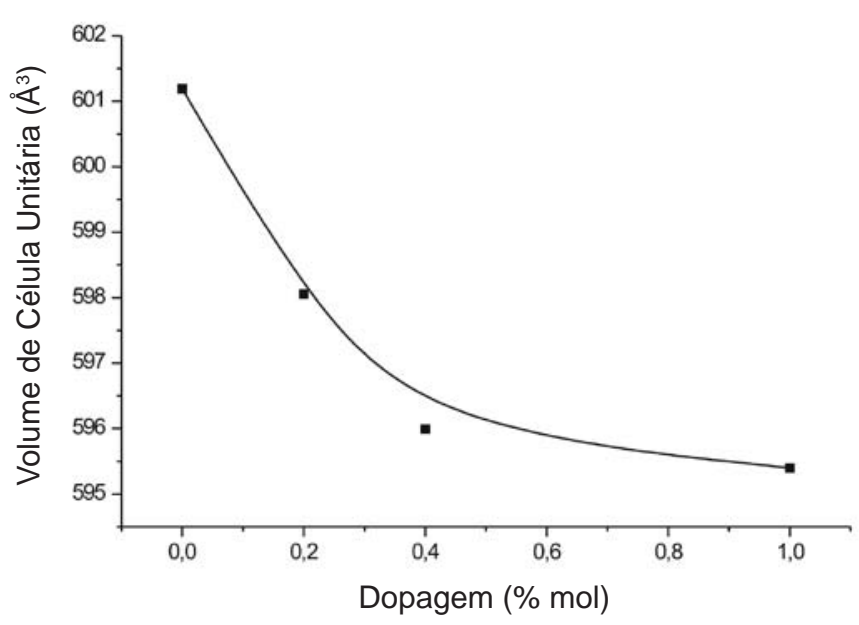

Figura 6: Volume da célula unitária de $\mathrm{Zn}_{2} \mathrm{Ti}_{1-\mathrm{x}} \mathrm{O}_{4}$ considerando uma quantidade de dopante.

[Figure 6: Volume of unit cell of $\mathrm{Zn}_{2} \mathrm{Ti}_{1-\mathrm{x}} \mathrm{O}_{4}$ as a function of the amount of dopant.] que os cátions de $\mathrm{V}^{5+}$, podem estar sendo forçados a entrar em posições que não são muito satisfatórias, dificultando o processo de difusão, mesmo a uma temperatura em que o pó se encontra num estado totalmente amorfo.

Os resultados de tamanho de cristalito, em função da concentração de vanádio, são apresentados na Fig. 8. As amostras apresentaram uma dispersão de valores à medida que aumenta a concentração do cátion substituinte $\mathrm{V}^{5+}$. Isso provavelmente se dá pelo fato de o vanádio ter mais dificuldade em entrar na estrutura, bem como a dificuldade em formar compostos com ligações $\sigma \mathrm{M}-\mathrm{C}$, na resina. Observase que a 0,2 mol\% de vanádio obteve-se menor tamanho de cristalito no sistema.

Os espectros fotoluminescentes são ilustrados na Fig 9. Os pós cerâmicos foram preparados e obtidos utilizando um tempo de 16 h de calcinação, em atmosfera de oxigênio, a uma temperatura de $300{ }^{\circ} \mathrm{C}$. A calcinação em atmosfera de oxigênio foi realizada com o objetivo de eliminar o carbono presente no carvão, sem promover uma cristalização. Observa-se que o $\mathrm{Zn}_{2} \mathrm{TiO}_{4}$, em seu estado puro, já apresenta características fotoluminescentes. Verificou-se que a adição do vanádio ao sistema favoreceu o aumento da propriedade fotoluminescente. A estrutura dos compostos $\mathrm{V}_{2} \mathrm{O}_{5}$ é semelhante a octaédrica, com um dos vértices desocupados, formando oxigênios não ponteantes. Acredita-se que isto pode ter gerado a propriedade fotoluminescente neste material. Observou-se que com $0,2 \%$ mol de vanádio o sistema apresentou maior in- 
Tabela I - Resultado de TG/ATD referente à perda da massa de carvão durante o primeiro estágio da decomposição térmica. [Table I- TG/DTA results referring to the coal mass loss during the first stage of thermal decomposition.]

\begin{tabular}{lccccc}
\hline \multirow{2}{*}{ AMOSTRAS } & \multicolumn{2}{c}{ 10 ESTÁGIO } & \multicolumn{2}{c}{ DTA $\left({ }^{\circ} \mathrm{C}\right)$} & \multirow{2}{*}{ \% PERDA DE MASSA } \\
& $\mathrm{T}_{\text {inicial }}\left({ }^{\circ} \mathrm{C}\right)$ & $\mathrm{T}_{\text {final }}\left({ }^{\circ} \mathrm{C}\right)$ & 1 $^{\text {a }}$ Transição & 2 ${ }^{\text {a }}$ Transição & 7,5 \\
\hline $\mathrm{Zn}_{2} \mathrm{TiO}_{4}$ & 65 & 185 & 431 & - & - \\
$\mathrm{Zn}_{2} \mathrm{Ti}_{\mathrm{x}} \mathrm{O}_{4}(\mathrm{x}=1,0 \%$ de $\mathrm{V})$ & 68 & 180 & 378 & 4,34 \\
\hline
\end{tabular}

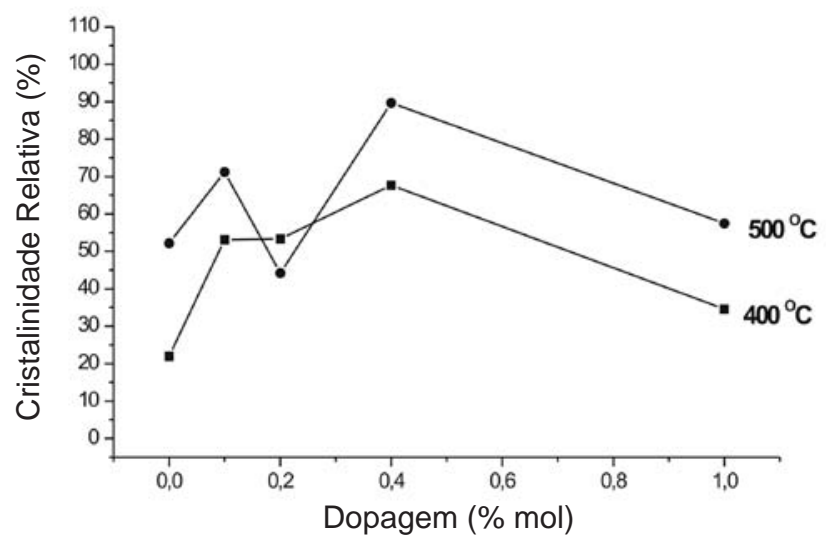

Figura 7: Cristalinidade relativa de $\mathrm{Zn}_{2} \mathrm{Ti}_{1-\mathrm{x}} \mathrm{O}_{4}$ de acordo com a quantidade de dopante.

[Figure 7: Relative crystallinity of $\mathrm{Zn}_{2} \mathrm{Ti}_{1-\mathrm{x}} \mathrm{O}_{4}$ as a function of the amount of dopant.]

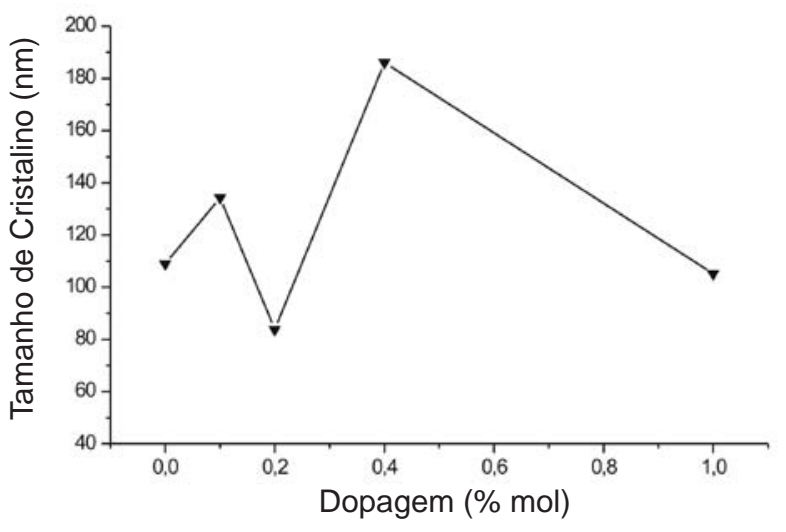

Figura 8: Tamanho do cristalito de $\mathrm{Zn}_{2} \mathrm{Ti}_{1-\mathrm{x}} \mathrm{O}_{4}$ de acordo com a quantidade de dopante.

[Figure 8: Crystallite size for $\mathrm{Zn}_{2} \mathrm{Ti}_{1-\mathrm{x}} \mathrm{O}_{4}$ as a function of the amount of dopant.]

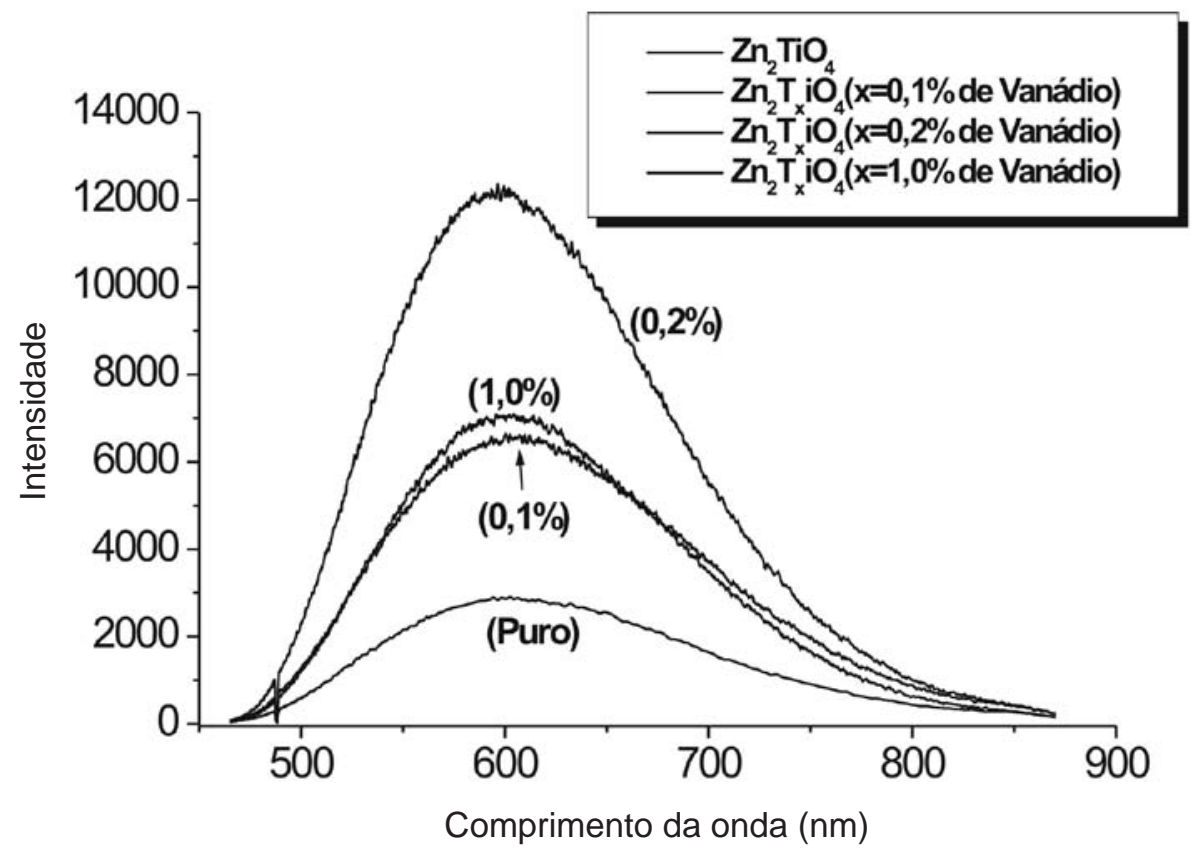

Figura 9: Espectros de fotoluminescência de of $\mathrm{Zn}_{2} \mathrm{Ti}_{1-\mathrm{x}} \mathrm{O}_{4}$ de acordo com a quantidade de dopante. [Figure 9: Photoluminescent spectra for $\mathrm{Zn}_{2} \mathrm{Ti}_{1-\mathrm{x}} \mathrm{O}_{4}$ as a function of the amount of dopant.] 
tensidade da propriedade fotoluminescente, resultado este que pode estar de acordo com o tamanho de cristalito.

\section{CONCLUSÕES}

A síntese do titanato $\left(\mathrm{Zn}_{2} \mathrm{TiO}_{4}\right)$ de zinco dopado com o metal de transição vanádio apresentou dificuldade de entrar na rede polimérica que resultou na segregação do sistema. Os resultados de parâmetro de rede determinaram que a adição do dopante promove uma diminuição do volume da célula unitária. Os espectros fotoluminescentes indicam que a adição do íon $\mathrm{V}^{5+}$, na estrutura favorece um aumento da propriedade.

\section{AGRADECIMENTOS}

Os autores agradecem ao CNPq e ao CMDMC pelo apoio no desenvolvimento deste trabalho

\section{REFERÊNCIAS}

[1] F. Zasso, Cassimiro, A Influência da Granulometria de Corantes e Esmaltes no Desenvolvimento das Cores, Cerâ- mica Industrial 2, 3/4 (1997) 41.

[2] L. T.Canham, Appl. Phys. Lett. 57 (1990) 1046.

[3] J. Ballato, R. Esmacher, R. Schwartz, M. Dejneka, J. Luminescence 86 (2000) 101.

[4] H. Liu, S. T. Li, G. K. Liu, W. Jia, F. E. Fernzandez, J. Luminescence 83-84 (1999) 367.

[5] P. S, Pizani, E. R, Leite, F. M, Pontes, E. C. Paris, J. H. Rangel, E. J. H. Lee, J. A. Varela, P. Delega, Appl. Phys. Lett. 77, 6 (2000) 824.

[6] S. J .Marin, M. O’Keeffe, D. E. Partin, J. Solid State Chem. 113 (1994) 413.

[7] X. Jinggang, C. Xiaoyu, L. Jinxia, Z. Hui, X. Yongyao, Z. Yunhong, 4 (2005) 289.

[8] B.V. Raghavaiah, C. L. Kanth, D. K. Rao, J. L. Rao, N. Veeraiah, Mater. Lett. 59, 5 (2005)539.

[9] M. P. Pechini, US Patent 3.330.697 (1967).

[10] M. Kakihana, J. Sol-Gel Sci. Techn. 6 (1996) 7.

[11] J. D. Lee, Química Inorgânica não tão Concisa, 4ª ed., Edgard Blucher Ltda., S. Paulo (1996) 20-22.

[12] W. D. Kingery, H. K. Bowen, D. R. Uhlmann, Introduction to Ceramics, $2^{\text {nd }}$ edition, John Wiley \& Sons, Nova York (1976). 